\title{
TSH reference values in the first trimester of gestation and correlation between maternal TSH and obstetric and neonatal outcomes: a prospective Brazilian study
}

Pedro Weslley Rosario', Marina Carvalho', Maria Regina Calsolari ${ }^{1}$

1 Programa de Pós-graduação, Serviço de Endocrinologia, Santa Casa de Belo Horizonte, Belo Horizonte, MG, Brasil

\section{Correspondence to:} Pedro Weslley Rosario Instituto de Ensino e Pesquisa, Santa Casa de Belo Horizonte Rua Domingos Vieira, 590 30150-240 - Belo

Horizonte, MG, Brasi pedrowsrosario@gmail.com

Received on Aug/12/2015 Accepted on Oct/29/2015

\begin{abstract}
Objective: To define the normal range of TSH in the first trimester of gestation and to evaluate the correlation between maternal TSH and obstetric and neonatal outcomes. Subjects and methods: Prospective study. Women without known or clinically suspected thyroid disease and without risk factors for thyroid dysfunction, who became pregnant spontaneously and were initially evaluated up to week 12 of gestation, were included. Women with positive anti-thyroperoxidase antibodies, twin pregnancy, hyperemesis gravidarum, and trophoblastic disease were excluded. Results: In the 660 pregnant women, the mean, median, and $2.5^{\text {th }}$ and $97.5^{\text {th }}$ percentiles of TSH were $0.9,0.96,0.04$ and $2.68 \mathrm{mIU} / \mathrm{L}$, respectively. TSH was undetectable in $2 \%,<0.5 \mathrm{mIU} / \mathrm{L}$ in $17.4 \%,>2 \mathrm{mlU} / \mathrm{L}$ in $9.7 \%$, $>2.5 \mathrm{mlU} / \mathrm{L}$ in $4.7 \%$, and $>3 \mathrm{mlU} / \mathrm{L}$ in $1 \%$. None of the women received levothyroxine or antithyroid drugs during pregnancy. In addition, there was no difference in obstetric or neonatal outcomes when women with TSH $\leq 0.1$, between 0.1 and 2.5 , and between 2.5 and $4 \mathrm{mIU} / \mathrm{L}$ were compared. Conclusion: In the population studied, the TSH value corresponding to the $97.5^{\text {th }}$ percentile was 2.68 $\mathrm{mIU} / \mathrm{L}$ in the first trimester of gestation. Arch Endocrinol Metab. 2016;60(4):314-8
\end{abstract}

Keywords

TSH; pregnant women; first trimester; reference values; obstetric and neonatal outcomes

\section{INTRODUCTION}

$\mathrm{T}$ $\mathrm{SH}$ is the most important test for the evaluation of thyroid function during pregnancy. Its measurement is essential for the diagnosis of primary thyroid dysfunction and is usually sufficient to exclude or suspect this condition. Supporting its importance, levothyroxine (L-T4) replacement therapy should be considered in pregnant women with elevated TSH, even in the presence of normal $\mathrm{T} 4$ concentrations and in the absence of anti-thyroperoxidase antibodies (TPOAb) (1-4), while L-T4 treatment is controversial in pregnant women with normal TSH, even in the presence of hypothyroxinemia or circulating TPOAb (1-4).

Serum TSH concentrations during pregnancy are not the same as those observed in nonpregnant women, and specific reference values are necessary. In this respect, knowledge of the normal range of TSH in the first trimester is the most important. First, greater differences in the concentrations of this hormone between pregnant and non-pregnant women are observed during this period (5). The extremely high circulating human chorionic gonadotropin (hCG) levels achieved in the first trimester activate the TSH receptor and thus directly stimulate the thyroid to produce more thyroid hormone which results in decreased TSH secretion. Second, before about 12 weeks of gestation, when the fetal thyroid gland becomes active, the mother is the sole source of thyroid hormones and maternal thyroid sufficiency might therefore be most important in the first trimester (6). Finally, there is agreement that, when indicated, screening for thyroid dysfunction should be conducted on the first prenatal visit (1-4), which generally occurs during the first months of pregnancy.

Rigorous selection of the sample is necessary to establish TSH reference values in pregnancy since, in addition to the habitually required exclusion criteria [known or clinically suspected thyroid disease, goiter, 
neck radiotherapy, personal history of autoimmune disease, family history of thyroid disease, drugs, and TPOAb $(7,8)]$, there are potentially interfering obstetric conditions [twin pregnancy, hyperemesis gravidarum, trophoblastic disease (5)].

The objective of this prospective study was to define TSH reference values in the first trimester of gestation for a Brazilian population, and to correlate maternal TSH concentrations with obstetric and neonatal outcomes.

\section{SUBJECTS AND METHODS}

\section{Prospective study}

The population studied was from the metropolitan region of Belo Horizonte (Minas Gerais, Brazil). Pregnant women who underwent prenatal exams at a clinical analysis laboratory and who had become pregnant spontaneously were initially interviewed and examined (9). Serum samples were obtained from the women in the morning (at about 8 a.m.) after an 8- to 10-h fast (9). Seven hundred and forty-eight women who met the clinical criteria shown in Table 1 were first selected (9). Next, TPOAb and TSH were measured. TPOAb-positive pregnant women were excluded. Women with hyperemesis gravidarum, twin pregnancy or trophoblastic disease were also excluded (5).

The final sample consisted of 660 women [a sample size larger than that required by the NACB (7)] ranging in age from 18 to 36 years (median 26.5 years), with a median gestation of 9 weeks, including 350 primigravidae.

Table 1. Inclusion criteria

Clinical criteria
Absence of thyroid disease, no current or previous treatment with antithyroid
drugs or L-T4, no history of ${ }^{131}$ I therapy or thyroidectomy
No use of potentially interfering medications such as dopaminergic agonists or
antagonists, neuroleptics, corticosteroids, estrogen, amiodarone, interferon,
lithium, anticonvulsants, metformin, octreotide; or recent (in the past 8 weeks)
exposure to iodinated contrast agents
No history of head and neck external radiotherapy
Absence of type 1 diabetes or other autoimmune diseases
No family history of thyroid disease
Absence of goiter or any palpable thyroid anomaly
Absence of ophthalmopathy
Complementary criteria: $\leq 12$ weeks gestation and TPOAb negative

Obstetric and neonatal outcomes were analyzed.

The study was approved by the local Research Ethics Committee (Santa Casa de Belo Horizonte).

TSH was measured with a chemiluminescent assay (Immulite 2000, Diagnostic Products Corporation, Los Angeles, CA), with reference values of 0.4-4 $\mathrm{mIU} / \mathrm{L}$, a functional sensitivity of $0.02 \mathrm{mIU} / \mathrm{L}$, and intra- and interassay coefficients of variation $<7 \%$ for values ranging from 0.1 to $40 \mathrm{mIU} / \mathrm{L}$. TPOAb were also measured with a chemiluminescent assay (Immulite 2000), with reference values of up to $35 \mathrm{kIU} / \mathrm{L}$.

The reference limits of normal TSH were defined as follows: 1) $2.5^{\text {th }}$ and $97.5^{\text {th }}$ percentiles of the values obtained for the sample; 2) logarithmic transformation of the values obtained, calculation of the mean \pm 1.96 SD of these values, and exponentiation to obtain the limits corresponding to the original scale (7). Fisher's exact or $\chi^{2}$ test were used to compare groups. P values $<0.05$ were considered statistically significant.

\section{RESULTS}

Figure 1 shows the distribution of TSH values in the sample. The mean, median, maximum, and $2.5^{\text {th }}$ and $97.5^{\text {th }}$ percentiles of the values obtained were $0.9,0.96$, $3.8,0.04$ and $2.68 \mathrm{mIU} / \mathrm{L}$, respectively. TSH was undetectable in $2 \%$ of the pregnant women, $<0.5 \mathrm{mIU} / \mathrm{L}$ in $17.4 \%,>2 \mathrm{mIU} / \mathrm{L}$ in $9.7 \%,>2.5 \mathrm{mIU} / \mathrm{L}$ in $4.7 \%$, and $>3 \mathrm{mIU} / \mathrm{L}$ in $1 \%$. We found no difference in TSH values between primigravidae versus multigravidae $(\mathrm{p}=$ $0.51)$.

The upper-reference limit (mean + 1.96 SD) was estimated for the log-transformed data and then exponentiated back to the original scale. The resulting value $(2.71 \mathrm{mIU} / \mathrm{L})$ was very close to the $97.5^{\text {th }}$ percentile of the TSH values $(2.68 \mathrm{mIU} / \mathrm{L})$.

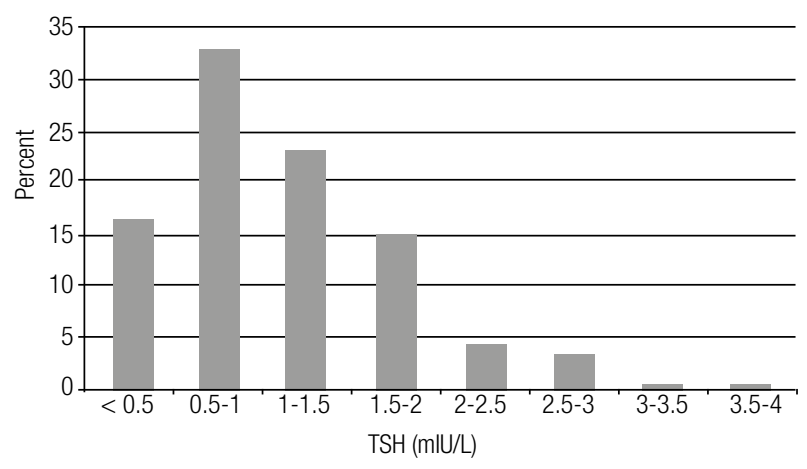

Figure 1. TSH distribution for the entire cohort $(n=660)$. 
None of the pregnant women were treated with L-T4 or antithyroid drugs up to the end of pregnancy. Table 2 shows the obstetric and neonatal outcomes according to maternal TSH concentrations in the first trimester of gestation.

\section{DISCUSSION}

We first highlight some characteristics of the study. This is the largest Brazilian study evaluating TSH concentrations in healthy pregnant women, in which the number of participants was much higher than that recommended by the NACB (7), selection was performed rigorously (clinical and TPOAb), including potentially interfering obstetric conditions (5), and the samples were adequately obtained (after fasting and in the morning in all participants). Ultrasonography (US) was not performed because of the following reasons: (i) US is not required by the National Academy of Clinical Biochemistry [NACB (7)]; (ii) studies have shown no change in the reference limits of normal TSH when subjects with ultrasonographic anomalies were excluded from the initial sample (10-14), a finding also demonstrated in a previous study from our group (15); (iii) no consensus exists regarding the ultrasonographic findings to be considered (10-14), and (iv) many of the subjects with US suggestive of chronic thyroiditis without circulating TPOAb are identified based on a personal history of autoimmune disease, a family history of thyroid disease or presence of goiter, which were exclusion criteria in the present study.

Our study confirms that low TSH concentrations are relatively frequent in the first trimester of gestation. TSH $<0.5 \mathrm{mIU} / \mathrm{L}$ was observed in $17.4 \%$ of the pregnant women studied and $\leq 0.05 \mathrm{mIU} / \mathrm{L}$ in $3 \%$. The main explanation for this finding is the action of HCG on the TSH receptor, which increases the secretion of thyroid hormones, with a consequent reduction in TSH. In fact, none of the women with undetectable TSH at the beginning of pregnancy had a history of thyroid disease, ophthalmopathy, goiter, palpable nodules, or TPOAb (exclusion criteria). The demonstration that low and even undetectable TSH in the presence of normal thyroid hormone concentrations in the first trimester of gestation is not associated with negative outcomes (16), and may even be a protective factor against some outcomes $(16,17)$, supports the physiological nature of this finding. Therefore, treatment of pregnant women with antithyroid drugs should only be considered when undetectable TSH is accompanied by elevated levels of $\mathrm{T} 4$ and/or T3 and in the presence of underlying thyroid disease (most frequently Graves' disease).

The upperlimitofnormal forTSHisthemostimportant parameter in clinical practice for both adjustment of the L-T4 dose in patients receiving hormone replacement therapy and the indication of this therapy (1-4).

Table 2. Obstetric and neonatal outcomes according to maternal TSH concentrations in the first trimester of gestation

\begin{tabular}{|c|c|c|c|}
\hline \multirow{2}{*}{ Obstetric and neonatal outcomes } & \multicolumn{3}{|c|}{ Maternal TSH concentration } \\
\hline & $<0.1 \mathrm{mIU} / \mathrm{L}(\mathrm{n}=33)^{\mathrm{a}}$ & $0.1-2.5 \mathrm{mlU} / \mathrm{L}(\mathrm{n}=596)$ & $2.5-4 \mathrm{mIU} / \mathrm{L}(\mathrm{n}=31)$ \\
\hline Hypertensive disease of pregnancy ${ }^{b}$ & $1(3 \%)$ & $54(9 \%)$ & $3(9.6 \%)$ \\
\hline Placental abruption & 0 & $2(0.3 \%)$ & 0 \\
\hline Delivery before 34 weeks of gestation & 0 & $6(1 \%)$ & 0 \\
\hline Delivery before 37 weeks of gestation & $1(3 \%)$ & $18(3 \%)$ & $1(3.2 \%)$ \\
\hline Fetal loss (after initial evaluation) & $1(3 \%)$ & $18(3 \%)$ & $1(3.2 \%)$ \\
\hline Birth weight $<2,500 \mathrm{~g}$ & $2(6 \%)$ & $35(5.8 \%)$ & $2(6.4 \%)$ \\
\hline Birth weight $<1,500 \mathrm{~g}$ & 0 & $9(1.5 \%)$ & 0 \\
\hline Need for intensive therapy & 0 & $12(2 \%)$ & $1(3.2 \%)$ \\
\hline Need for mechanical ventilation $>24 \mathrm{~h}$ & 0 & $12(2 \%)$ & $1(3.2 \%)$ \\
\hline Necrotizing enterocolitis ${ }^{c}$ & 0 & $1(0.16 \%)$ & 0 \\
\hline Intraventricular hemorrhage grade 3 or 4 & 0 & 0 & 0 \\
\hline Major congenital malformations & 0 & $6(1 \%)$ & 0 \\
\hline Neonatal death (<28 days) & 0 & $3(0.5 \%)$ & 0 \\
\hline
\end{tabular}


In contrast to low $\mathrm{TSH}$, which alone is not an indication for treatment, in pregnant women with elevated TSH L-T4 replacement therapy is indicated even in the presence of normal T4 concentrations and in the absence of TPOAb (1-4). Furthermore, normal TSH weakens the indication for hormone replacement therapy even in the presence of hypothyroxinemia or circulating TPOAb (1-4). Although recent guidelines propose a value of $2.5 \mathrm{mIU} / \mathrm{L}$ as the upper limit for TSH in the first trimester of gestation (1-4), they recognize that population variations are possible and that it is important to obtain specific values. Hence, the importance of studies like this.

Our results showed a $97.5^{\text {th }}$ percentile of TSH of $2.7 \mathrm{mIU} / \mathrm{L}$ and $<5 \%$ of pregnant women with $\mathrm{TSH}$ $>2.5 \mathrm{mIU} / \mathrm{L}$. In contrast, also for the Brazilian population, another smaller series $(n=127)$ found higher TSH concentrations at the end of the first trimester, with a $97.5^{\text {th }}$ percentile of $4.43 \mathrm{mIU} / \mathrm{L}$ and $11 \%$ of pregnant women with TSH $>2.5 \mathrm{mIU} / \mathrm{L}$ (18). Indeed, the upper limit of normal for TSH in the first trimester was $>2.5 \mathrm{mIU} / \mathrm{L}$ in many studies, with the $95^{\text {th }}$ percentile reaching $5 \mathrm{mIU} / \mathrm{L}(1,19,20)$. One may thus conclude that TSH concentrations $<2.5 \mathrm{mIU} / \mathrm{L}$ at the beginning of pregnancy are normal, while concentrations $>5 \mathrm{mIU} / \mathrm{L}$ would be clearly altered. The doubt remains whether TSH between 2.5 and $5 \mathrm{mIU} / \mathrm{L}$, especially in the absence of TPOAb and hypothyroxinemia, necessarily indicates thyroid dysfunction. Negro and cols. (21) compared TPOAb-negative pregnant women with TSH $<2.5$ $\mathrm{mIU} / \mathrm{L}$ and between 2.5-5 $\mathrm{mIU} / \mathrm{L}$ at the beginning of pregnancy and found a higher rate of fetal loss in the latter. No difference in the rate of prematurity was observed in that study (21). Furthermore, it is unclear whether L-T4 replacement therapy in patients with TSH between 2.5 and $5 \mathrm{mIU} / \mathrm{L}$ would normalize a possible increased risk. Despite the small sample, we found no additional obstetric or neonatal outcomes in TPOAb-negative women with TSH between 2.5 and $4 \mathrm{mIU} / \mathrm{L}$ versus $\mathrm{TSH}<2.5 \mathrm{mIU} / \mathrm{L}$. It has also been suggested that, within the first trimester of gestation, TSH concentrations until week 6 would be the same as those observed in non-pregnant women and would decrease only after week 7 (20).

In conclusion, our results suggest an upper limit of $2.7 \mathrm{mIU} / \mathrm{L}$ for TSH in the first trimester of gestation.

Disclosure: no potential conflict of interest relevant to this article was reported.

\section{REFERENCES}

1. Stagnaro-Green A, Abalovich M, Alexander E, Azizi F, Mestman $\mathrm{J}$, Negro R, et al. Guidelines of the American Thyroid Association for the diagnosis and management of thyroid disease during pregnancy and postpartum. Thyroid. 2011;21:1081-125.

2. De Groot L, Abalovich M, Alexander EK, Amino N, Barbour L, Cobin $\mathrm{RH}$, et al. Management of thyroid dysfunction during pregnancy and postpartum: an Endocrine Society clinical practice guideline. J Clin Endocrinol Metab. 2012;97:2543-65.

3. Garber JR, Cobin RH, Gharib H, Hennessey JV, Klein IL, Mechanick $\mathrm{Jl}$, et al.; American Association Of Clinical Endocrinologists And American Thyroid Association Taskforce On Hypothyroidism In Adults. Clinical practice guidelines for hypothyroidism in adults: cosponsored by the American Association of Clinical Endocrinologists and the American Thyroid Association. Thyroid. 2012;22:1200-35.

4. Lazarus J, Brown RS, Daumerie C, Alicja Hubalewska-Dydejczyk A, Negro R, Vaidya B. 2014 European Thyroid Association guidelines for the management of subclinical hypothyroidism in pregnancy and in children. Eur JThyroid. 2014;3:76-94.

5. Panesar NS, Li CY, Rogers MS. Reference intervals for thyroid hormones in pregnant Chinese women. Ann Clin Biochem. 2001;38:329-32.

6. Haddow JE, Palomaki GE, Allan WC, Williams JR, Knight GJ, Gagnon J, et al. Maternal thyroid deficiency during pregnancy and subsequent neuropsychological development of the child. $\mathrm{N}$ Engl J Med. 1999;341:549-55.

7. Baloch Z, Carayon P, Conte-Devolx B, Demers LM, FeldtRasmussen U, Henry JF, et al. Laboratory medicine practice guidelines. Laboratory support for the diagnosis and monitoring of thyroid disease. Thyroid. 2003;13:3-126.

8. Rosario PW, Xavier AC, Calsolari MR. TSH reference values for adult Brazilian population. Arq Bras Endocrinol Metabol. 2010;54:603-6.

9. Rosario PW, Purisch S. Thyroid dysfunction in pregnancy: definition of TSH cut-off should precede the decision of screening in low-risk pregnant women. Gynecol Endocrinol. 2011;27:205-8.

10. Volzke H, Alte D, Kohlmann T, Ludemann J, Nauck M, John U, et al. Reference intervals of serum thyroid function tests in a previously iodine-deficient area. Thyroid. 2005;15:279-85.

11. Zöphel K, Wunderlich G, Grüning T, Koch R, Döge H, Kotzerke J. Where does subclinical hypothyroidism start? Implications for the definition of the upper reference limit for thyroid stimulating hormone (TSH). Nuklearmedizin. 2005;44:56-61.

12. Hamilton TE, Davis S, Onstad L, Kopecky KJ. Thyrotropin levels in a population with no clinical, autoantibody, or ultrasonographic evidence of thyroid disease: implications for the diagnosis of subclinical hypothyroidism. J Clin Endocrinol Metab. 2008;93:1224-30.

13. Kratsch J, Fiedler GM, Leichtle A, Brugel M, Buchbinder S, Otto $L$, et al. New reference intervals for thyrotropin and thyroid hormones based on National Academy of Clinical Biochemistry criteria and regular ultrasonography of the thyroid. Clin Chem. 2005;51:1480-6.

14. Fontes R, Coeli CR, Aguiar F, Vaisman M. Reference interval of thyroid stimulating hormone and free thyroxine in a reference population over 60 years old and in very old subjects (over 80 years): comparison to young subjects. Thyroid Res. 2013;6:13.

15. Borges MAR, Rosario PW, Purisch S. Normal serum TSH for our adult population. Congresso Mineiro de Endocrinologia 2007 (Abstract).

16. Casey BM, Dashe JS, Wells CE, Mclntire DD, Leveno KJ, Cunningham FG. Subclinical hyperthyroidism and pregnancy outcomes. Obstet Gynecol. 2006;107:337-41. 
17. Tudela CM, Casey BM, Mclntire DD, Cunningham FG. Relationship of subclinical thyroid disease to the incidence of gestational diabetes. Obstet Gynecol. 2012;119:983-8.

18. Felipe $\mathrm{CL}$, Medina $\mathrm{CC}$, Sieiro NL, Alexandru B, Mario V. Is an upper limit of $2.5 \mathrm{mUl} / \mathrm{l}$ for TSH appropriate for the first trimester of pregnancy among young TPO - women? Gynecol Endocrinol. 2010;26:54-7.

19. Marwaha RK, Chopra S, Gopalakrishnan S, Sharma B, Kanwar RS, Sastry A, et al. Establishment of reference range for thyroid hormones in normal pregnant Indian women. BJOG. 2008;115:602-6.
20. Li C, Shan Z, Mao J, Wang W, Xie X, Zhou W, et al. Assessment of thyroid function during first-trimester pregnancy: What is the rational upper limit of serum TSH during the first trimester in Chinese pregnant women? J Clin Endocrinol Metab. 2014;99: 73-9.

21. Negro R, Schwartz A, Gismondi R, Tinelli A, Mangieri $T$, Stagnaro-Green $A$. Increased pregnancy loss rate in thyroid antibody negative women with TSH levels between 2.5 and 5.0 in the first trimester of pregnancy. J Clin Endocrinol Metab. 2010;95:E44-8. 